\title{
C.ONTRIBUCIÓN A LA TEORÍA DE LOS VALORES
}

Nos proponemos desarrollar en el siguiente ensayo un comentario a la teoría general de los valores, con objeto de intentar alguna contribución en esta debatida cuestión que constituye el tema central de la filosofía moderna; el punto de vista que emplearemos para conducirlo es el que dirige la reflexión antropológica, entendida no en el sentido empírico de la "antropología científica", ni tampoco en el abstracto de la "antropología filosófica", sino a través de un criterio que consideramos dialéctico y funcional, apegado al método crítico, cuya trascendentalidad permite observar con la mayor amplitud el campo fenoménico al cual se dirige, y que es en este caso el de la cultura humana, donde se funde el hombre con el mundo que lo rodea en una paradoja sutil que no es fácil de captar, culminando los factores objetivo y subjetivo que se vinculan indisolublemente en el hecho cultural, y paralelamente a él, en el mundo de los valores.

La ubicación de la axiología en el ámbito antropológico podría parecer una burda recaida en el subjetivismo si no fuera porque hemos advertido sobre la paradoja del pensar, que une al mundo interno y al mundo externo mediante la idea del valor. Esta idea es la que tiene mayor significación para el hombre, pues en última instancia el denominador común de lo humano es el valor; sólo existe para el hombre lo que vale para él. De ahí la identidad de ser y valer que tan difícilmente se expresa y más difícilmente aún se capta en su auténtico sentido. La axiología es la máxima filosofía y la suprema antropología, pues la funcionalidad objetivo-subjetiva se manifiesta idóneamente en el concepto del valor.

El sistema axiológico posee una ambivalencia que se difunde en todos los campos de la vida; los que pertenecen al hombre recaen bajo el concepto del mundo interno, y los que conciernen a la naturaleza se cubren bajo el símbolo del mundo externo. Por ello, al contestar a la pregunta crucial: $i Q u e ́$ es el valor? respondemos por modo reflejo al primer interrogante de nuestras meditaciones: ¿Qué es el hombre? y también a la cuestión que se sitúa en la mampara de la filosofía: ¿Qué es el mundo? He ahí la síntesis del mundo externo y el mundo interno, ser y valer; en esta síntesis, en esta dualidad, se encuentra la motivación esencial de la axiología.

La inclinación del hombre hacia determinadas finalidades se manifiesta a través de su conducta objetiva, y con toda preferencia en la acción cultural, donde se acendran los valores en forma de obra perdurable. La cultura es 
fruto de la expresión espiritual que se proyecta en el mundo exterior y refleja simultáneamente ambos factores, el sujeto y el objeto, sirviendo como base para la excogitación del mundo interno y el mundo externo, vale decir, de la antropología y la filosofía, el ser y el valer.

Los valores no pueden concebirse a espaldas de su expresión cultural, pues sin ella quedarían inoperantes, como formas vacías de la imaginación; imaginar un valor no es realizarlo, así como pensar en algo no equivale a construirlo. Para convertir al valor en obra se requiere del acto creador por el cual un proyecto se transforma en realidad, un propósito en un hecho. El campo de la facticidad axiológica es la cultura y en ella se presentan los valores como algo dado, como actos que efectúa el espíritu por la compulsión de ser y vivir, de progresar y comunicar este progreso a los demás.

La equivalencia de cultura y valores nos hace partir de la primera y proseguir a la génesis de los segundos, mediante la relación objeto-sujeto que figura como base de la axiología. La unidad de los valores y la cultura evita el tipo de concepciones abstractas que se emiten con frecuencia, soslayando a la realidad para caer en un utopismo inoperante. El caso contrario corresponde a llana observación de la existencia, limitándose a una comprobación empírica de los acontecimientos sin buscar su fundamento de valor; el extremo de este empirismo es la narración escueta de los hechos, que degenera en la crónica intrascendente y la erudición anómica. Ambos casos se han producido con frecuencia en la teoría del valor y la importancia de evitarlos se mide por el perjuicio que ocasionan al sistema integral de la cultura, manteniendo alguno de sus campos a costa de mutilar a los demás.

La relación que se funda entre los valores y la cultura nos lleva directamente a otra relación que incide en la fuente creadora del espíritu. El sentido de esta relación se traduce en la apetencia que suscita un objeto en el hombre, en virtud de cierta afinidad que se establece entre el contenido de valor y el carácter individual. La relación misma denota el origen subjetivo de los valores y refleja el hecho de que la cultura es producida por los hombres que la promueven. La inclinación que muestra el sujeto frente a los valores, particularmente hacia alguno de ellos, es la clave para reconocer la realidad psíquica subyacente, convirtiendo a la elección del valor en sintoma de la constitución humana y de sus más nobles aspiraciones.

Esta doble virtud del valor, como símbolo y como síntoma, es la razón de incorporar a la axiología en la cumbre del sistema antropológico. La inversión que efectuamos del aforismo protagórico, al decir que "todas las cosas son la medida del hombre", encuentra su expresión más directa en la dimensión axiológica, permitiendo una fórmula tan expresiva como ésta: los valores son la medida del hombre. En efecto, la elección de un valor es el más elocuente signo de la existencia.

La atribución de valor que reciben los objetos de la naturaleza cuando 
ingresan en los intereses humanos, explica el viraje que ha ocurrido en la filosofía moderna, transfiriendo los problemas del ser a los del valer, a medida que el hombre extiende su radio de acción y engloba cada vez un mayor número de objetos. También esta convicción ha presentado un cariz extremo, que consiste en la incorporación total de la naturaleza bajo el concepto del valor, estableciendo una identidad absoluta entre ser y valer, de la cual nos ocuparemos con posterioridad. El principio que afirmamos como postulado axiológico es la atribución humana del valor, quedando en pie el concepto establecido: vale todo aquello que representa un interés para el hombre.

Ahora bien, aunque todos los elementos que intervienen en la vida adquieren un valor, no siempre poseen la misma importacia; son de diversa jerarquia, dependiendo del rango que acuse el interés humano al cual afectan. Por ejemplo, no tiene el mismo valor un principio tan importante como es la orientación de la vida, que el cumplimiento de un propósito intrascendente; de análoga manera, no posee el mismo valor un elemento que concierne a la materialidad del individuo, que uno donde se juega su trayectoria espiritual. Las condiciones que establecen la importancia de cada coeficiente han de ser objeto de mayores consideraciones; pero, en todo caso, queda incólume el principio que deseamos establecer y que puede enunciarse del siguiente modo: el valor que tiene un elemento en la vida del hombre depende del valor que posea el aspecto humano al cual interesa. Este principio refrenda la identidad de lo humano y el valor, no sólo en términos generales, sino también en los grados y modalidades que adquiere de acuerdo a su peculiar significación.

El acto valorativo ocupa un lugar preferente en la existencia desde el momento que se le destina a dirigirla, ya sea de modo consciente o inconsciente. El hombre norma su vida de acuerdo a los valores que acepta, no sólo por la validez intrínseca que puedan tener, sino también por la compulsión inconsciente que le imponen numerosas circunstancias. La realización de los valores equivale a la realización del individuo, y ésta le proporciona una estabilidad definitiva en su persona.

Los valores contribuyen a la personalidad, y aún más, la determinan totalmente, satisfaciendo la necesidad psicológica y formativa del individuo; no se trata de meras finalidades concebidas como propósitos abstractos, sino de algo más importante, que es la realización de la persona mediante el incremento de sus facultades, a un grado tal que pueda cumplir sus propósitos capitales. Cuando esto se logra, el ser humano percibe a los valores en él mismo, los posee no sólo al modo de quien los ha conquistado, sino en el más intimo de quien los ha producido, y en virtud de esta interna creación logra para su individualidad la fuerza dinámica y el controlado equilibrio que proporcionan el éxito en la vida. 
$\mathrm{La}$ intervención de los valores como coeficientes del asentamiento personal ha sido aquilatado por la psicologia moderna, especialmente en su dirección cultural, que contiene el punto de vista más amplio para explicar la conducta. El tener en cuenta la acción vital de los valores frente a la cultura ha hecho que la psicología supere el determinismo biológico de su primera etapa, donde consideraba a la conducta como un efecto de los instintos primarios que subyacen en el individuo como parte esencial de su contextura biológica. En vez de ello, la psicología cultural tiene en cuenta sobre un plano predominante a los conceptos vitales, que actúan positiva o negativamente, ya sean de creación directa o impuestos por la sociedad, tejiendo la cerrada urdimbre que polariza el efecto esencial de los valores, con una perspectiva de realización o frustración, de éxito o fracaso en la vida. Gran parte de los conflictos psicológicos se pueden explicar por ese doble efecto que tienen los valores en la existencia del hombre.

La producción del valor está rodeada por factores que dependen de la época y el lugar en que se encuentran, influyendo en todos los sectores de la valoración, en el sujeto que la efectúa, en el objeto donde recae, y en el medio que lo envuelve y determina. Ésta es la mutabilidad del valor y consiste en la variación con que se desenvuelven los coeficientes de lo humano, principalmente los de orden cultural e histórico, que se suceden en una rápida y constante evolución.

La determinación histórica de los valores ingresa en la motivación de la ciencia correspondiente, o sea la ciencia histórica, cuyo temario más profundo tiende a establecer lo que hay de constante y de mutable en la historia; este propósito tiene como centro de localización el concepto de valor, de suerte que ambas cuestiones pueden definirse en torno a la axiología, y preguntar: ¿cuáles han sido los valores preponderantes en cada época, y cuáles los que permanecen constantes en el decurso histórico? Este es el planteamiento axiológico, ubicado tradicionalmente en la filosofia de la historia, que investiga la evolutividad y permanencia de los conceptos históricos.

La conciencia individual de los valores constituye la base para su formulación concreta; cada ser humano debe tener en el fondo de su conducta y su actitud en la vida, la comprensión personal de los valores.

Sin embargo, éstos se difunden más allá del ámbito individual y cubren todo el campo de las relaciones humanas, alcanzando una dimensionalidad colectiva que los convierte en elementos básicos de la convivencia, organizada como una gran conciencia que tiende a la uniformación de sus propósitos, a la homogeneidad de sus valores, con objeto de nivelar la acción social y procurar que desempeñe la función normativa que requiere la convivencia. Esta necesidad de nivelación es el origen constitutivo de la sociedad y estabiliza la conducta de sus miembros con objeto de hacer más fecundo su convivio.

La dirección social de los valores se opone a la tendencia de originalidad 
que priva en cada hombre, queriendo convertirse en un mundo individual, en una esfera de valores que lo hagan irreductible a la sociedad. Cada ser humano alberga este propósito como una tendencia congénita a resaltar entre los demás y promover una lucha entre el poder uniformador de las normas sociales y la tendencia individualizadora de los valores personales. La resolución de la contienda se produce en lo que se ha llamado la "adaptación del individuo a la sociedad"; pero aun cuando ésta se efectúe, proseguirá el impulso al individualismo, que en vez de atenuarse por la convivencia, se ve reforzada por ella, pues no se limita a la realización de los valores individuales, sino procura su predominio frente a los ajenos para dar el consiguiente relieve a la personalidad.

La realización de los valores brinda una oportunidad extraordinaria para cimentar el entendimiento de los hombres, más allá de sus diferencias constitucionales y trascendiendo el medio en que se hayan formado así como el carácter que los determine. La aceptación de los valores es la parte medular en la comprensión social; son el núcleo más importante, más esencial y genuino del hombre, ofrecen la revelación subjetiva de su naturaleza y la manifestación objetiva de su conducta, teniendo como denominador común a la conciencia. La comprensión del hombre a través de los valores tiende al rescate de la subjetividad, a la superación del antagonismo en que se desenvuelven las convicciones internas, cuando son el fruto de una formación particular y no de una convicción universal.

Este rescate de los valores no significa la ruptura con la subjetividad ni tampoco su avasallamiento frente a la universalidad ideal; la axiología se funda en la comprensión racional de su validez, y por consiguiente, en la necesidad de aceptarlos como normas de vida; un valor que no tuviera de base dicha convicción sería un valor inoperante, o lo que es igual, un falso valor, un producto de la imaginación. Pero una vez que el valor se ha demostrado en su interna validez, se convierte en norma de acción, en mandato que es necesario acatar como forma de vida, elevándolo a categoría de principio moral.

No es una mera coincidencia que la razón suprema del valor sea la misma que rige a la concepción moral, a saber: el progreso. En efecto, si preguntamos por qué se postula un valor y se acepta el compromiso de realizarlo, la contestación no podrá ser otra que: el valor es bueno, análogamente a como la responsabilidad de la acción se contrae en términos de bondad. El valor es bueno; la moral es buena. De esta identidad entre la moral y lo bueno se desprenden consecuencias de enorme repercusión en la axiología, en la filosofía y en la vida misma. El valor debe ser bueno y también debe serlo la conducta; una existencia situada a espaldas del valor se colocará también en contra de la moralidad. La conciencia del valor culmina en la 
conciencia moral, así como la capacidad para orientarse en la vida depende de la facultad para comprender los valores.

Ahora bien, si después de afirmar a la bondad del valor como base de la concepción axiológica, se pregunta por qué se le ha de promover, agregaríamos que hay una razón superior a la bondad, cuando ésta es concebida meramente como una acción positiva, como un estado subsistente en sí y por sí. Esta razón es el incremento de la bondad, que va paralela a la insatisfacción de cualquier estado fijo, manteniendo la necesidad de ir siempre hacia arriba, de avanzar constantemente. Para nosotros el lema superior de la vida, el mandato supremo de la moralidad, es el siguiente: no basta ser bueno, hay que ser cada vez mejor. Con él llegamos al más elevado de los niveles filosóficos, al más sublime de los conceptos que pueda postular el hombre: el progreso. Más allá de esta postulación no existe ninguna razón superior, pues si preguntamos por qué es necesario ser cada vez mejor, sólo podrá responderse que se es mejor para ser mejor, porque indudablemente es mejor ser mejor que no serlo, es mejor ser mejor que estacionarse en un lugar fijo o retroceder a estados inferiores.

El último fundamento subjetivo de los valores radica en la necesidad de un continuo progreso, en la constante evolución de las formas vitales y en la producción de una obra cada vez más amplia, que subsista como testimonio de la inagotable vitalidad del espíritu, del ansia de mejoramiento que promueve a la humanidad.

Para avanzar en el estudio de los valores hay que establecer cuáles son sus caracteres esenciales, análogamente a como se hace con cualquier otro objeto. La determinación de dichos caracteres permite reconocer la esencia del problema correspondiente, desenvolverlo en todas sus consecuencias y fijarlo en sus conceptos fundamentales, una vez que se ha definido su autonomía en el método y el sistema de trabajo. Las características generales del valor son de gran importancia en el conocimiento, pues revelan su aspecto medular, y se conocen como categorias.

Las categorías axiológicas giran en torno a la definición del valor, que de esta suerte adquiere mayor importancia que cualquiera otra noción, no porque se presente con mayor frecuencia, sino porque establece el concepto esencial de los valores, fundado en una definición primaria que se encuentra a la base de todo su desarrollo y contiene la expresión sucinta del valor, o sean las notas que lo caracterizan inequivocamente.

Para exponer cuáles son las categorías axiológicas seguiremos una secuencia que principia con la definición del valor y desarrolla sus propiedades de acuerdo a su integración básica, partiendo de la función que sintetiza sus dos grandes vertientes, el espíritu y la naturaleza, el mundo interno y el 
mundo externo, cuya vinculación nos ha ocupado para explicar la génesis de la cultura. De esta suerte, encontramos las siguientes categorías:

a. La sintesis del mundo interno y el mundo externo; es la acción dinámica que efectúa la comunicación del hombre y la realidad.

$b$. Por su parte, la idealidad representa la esfera de las concepciones puras, que reflejan directamente la acción del espíritu.

c. La realidad es la categoría connotativa de la naturaleza y representa el mundo circundante que envuelve a la existencia del hombre.

$d$. Avanzando en la estructura del valor reconocemos su acción positiva frēnte a su desviación negativa, motivando una cuarta categoria que es la polaridad.

$e$. Ahora bien, como todos los valores admiten un concepto general que los unifica a través de su funcionalidad común, se desprende una nueva categoría que es la unidad.

f. Los valores se realizan mediante actos y disciplinas diferenciales, de donde la categoría de concreción, que indica la diversidad en obras y valores de la cultura.

g. Mas adelante, al observar la evolución integrativa de los valores se justifica una categoría como es la gradación, o sea la sucesión de los grados axiológicos en la escala progresiva de la evolución.

$h$. Nl hecho de que los valores nunca se realicen en forma absoluta sino dentro de ciertos límites y bajo determinadas condiciones, origina la categoría de relatividad.

i. La aplicación de los valores para satisfacer necesidades de la existencia es la razón para aceptar una categoría como la utilidad.

$j$. Por último, cualquier valor puede tener prioridad frente a los demảs, en determinadas condiciones, de donde la jerarquía que ostenta en su preeminencia. Así nos queda el siguiente

$$
\text { CUADRO DE LAS CATEGoRÍAS DEL VALOR }
$$

\begin{tabular}{|c|c|c|}
\hline \multirow{2}{*}{ Idealidad } & Sintesis & \multirow[b]{2}{*}{ Realidad } \\
\hline & & \\
\hline Unidad & Gradación & Concreción \\
\hline Relatividad & Jerarquía & Utilidad \\
\hline $\begin{array}{l}\text { Categorias } \\
\text { téticas }\end{array}$ & $\begin{array}{l}\text { Categorias } \\
\text { sintéticas }\end{array}$ & $\begin{array}{l}\text { Categorias } \\
\text { heterotéticas }\end{array}$ \\
\hline
\end{tabular}

Obsérvese la disposición que hemos dado a las categorías axiológicas. 
Están situadas en tres columnas; la del centro, encabezada por la síntesis, contiene las categorías primordiales del valor y establece la necesidad de concebirlo como sintesis de elementos opuestos. La primera columna contiene a las categorías ideales, o sean las que representan al espiritu, en tanto que la tercera recoge las categorías reales, que tienen su origen en la facticidad. Teniendo en cuenta que las categorías se enlazan en un proceso dialéctico, designaremos como representativas de la tesis a las del lado izquierdo, que serán categorías téticas, en tanto que las del lado derecho corresponderán a la heterotesis, y por ello mismo, serán categorías heterotéticas. En la columna central están las que desempeñan una función vinculatoria, recibiendo el nombre de categorías sintéticas.

Veamos ahora cuál es el significado de dichas categorías.

El desempeño que tiene la sintesis es precisamente como síntesis de elementos, y no podría subsistir si no fuera por los elementos que sintetiza. Ahora bien, su efecto consiste en una acción dinámica que conduce a la evolución, para lo cual se requiere efectuarla a través de elementos opuestos: y mientras más lo sean, tanto mejor para la dinámica que persigue, pues la oposición será más violenta y mayor la tendencia a resolverla. Si no fuera por esta unidad de los contrarios en la síntesis axiológica, no existiría la acción dinámica que promueve la evolución de la cultura.

Los elementos que participan en la síntesis son la realidad y la idealidad, extendida la primera como la materia que proporciona al hombre el vehículo de su expresión, en tanto que la idealidad es la virtud que tiene el espíritu de concebir ideas como base de los valores. Los dos factores de la síntesis actúan a la manera de polos en la dualidad dinámica; lo real y lo ideal se funden en la síntesis del valor, en la unidad de naturaleza y espíritu, cuya oposición se resuelve precisamente en la sintesis. En esta dualidad y su consiguiente oposición, descansa la síntesis del valor.

La idealidad del valor proviene fundamentalmente de la libertad que tiene el hombre para concebir sus ideales, o lo que equivale, sus finalidades en la vida. Esta libertad es la acción pristina de la conciencia, la manifestación de su potencialidad creativa y en ella se cifra lo más dignamente humano como es la facultad de postular valores. Si no fuera por esta libertad, la vida quedaría integramente sujeta a los requerimientos del medio, a la presión de las circunstancias, y en suma, a los factores ajenos al individuo. La posibilidad de autodecisión lo rescata de la constricción externa, de la imposición que ejerce el medio. Por ello, la libre facultad de elegir valores representa la categoría de idealidad.

Por más que la concepción ideal se efectúe en ejercicio de la libertad, ésta es un elemento constitutivo del hombre, queda sujeta a su modo de ser y actuar, a los caracteres que la determinan. La realidad del valor es un freno a la idealidad, un llamado de atención para que la virtud conceptiva 
no se convierta en imaginación pura, sino conserve la inmanencia que mantiene al hombre arraigado a la naturaleza. Si no fuera por la realidad, el valor quedaría como un producto de la imaginación, como un resultante neto de la subjetividad.

Al mismo tiempo, realidad equivale a objetividad, pues el contacto que mantiene con el mundo real permite su verificación, la comprobación de lo que ha concebido. La más elevada expresión de la objetividad consiste en la demostración de la verdad científica, que alcanza esta propiedad al verificarse en los objetos. De un modo más amplio, la realidad del valor se funda en su incorporación a la materia, que recibe la forma espiritual $y$, mediante la sintesis de ambos elementos, se convierte en obra de la cultura, en actos que señalan la fecunda unidad del espíritu y la materia.

Los valores no son entidades puras que se presenten inmaculados en la vida, la cual no es incondicionalmente positiva; tanto aquéllos como ésta se encuentran ligados a un contrapolo negativo que, para distinguirlo del valor propiamente dicho, se conoce como valor negativo, disualor o contravalor.

La acción del disvalor es contraria al valor positivo y se reconoce como contrapolo de lo que se haya postulado como valor positivo. Obviamente, no puede existir algo negativo sin lo que deniega, o sea el valor positivo, y como éste proviene de la libre elección de la conciencia, resulta de ahí que el valor primario es siempre positivo, y sólo como derivación nugatoria se concibe al disvalor.

El resultado de la polaridad axiológica es la alternativa de dirigirse por un camino bueno o malo en la vida, pudiendo variar, desde luego, el concepto del valor. Si no existiera la polaridad y todos los valores fueran integramente buenos, la vida sería uniforme y estaría inequívocamente orientada al bien; el simple hecho de concebirlo bastaría para asegurar su realización. Pero no sucede así, pues la existencia acusa actos buenos y malos, ideas que favorecen o entorpecen al progreso del hombre. Ahora bien, como lo incondicionalmente bueno es la acción para el progreso, de ahí resulta que será negativo lo que contribuya de un modo u otro a obstaculizarlo.

La unidad de los valores consiste, como lo indica el término, en el carácter que priva en cualquier tipo de valor, la esencia común que permite llamarlos "valores", a pesar de su diferente realización. La unidad axiológica se funda sobre el concepto del valor y a partir de él se constituye con una gran diversidad de funciones.

Ahora bien, ¿qué es el concepto del valor? Ya lo hemos dicho antes; el valor es ante todo un elemento de expresión espiritual, la proyección del hombre en sus obras. Vale todo lo que contribuye al desarrollo del hombre, ya sea en el aspecto material o espiritual; sustancialmente, el valor repercute en el progreso, en la continua evolución. La unidad de los valores es la 
humanidad y a partir de ella se comprenden todas sus manifestaciones, que en una forma u otra constituyen elementos de expresión humana, potencias que se exteriorizan en la vida.

De esta suerte obtenemos una doble acepción de la unidad axiológica, como unidad imperante en cada tipo de valor y al mismo tiempo como unidad coordinadora de todos los valores. Se trata en el fondo del mismo concepto, ya que en ambos casos se apoya en la acepción genérica del valor, que, según está dicho, debe realizarse en todas y cada una de sus manifestaciones; en el primer caso trataráse de la unidad genérica, mientras que el segundo reporta la unidad especifica, verificando doblemente el concepto del valor, o sea la expresión de lo humano.

Los valores se realizan en actos concretos, en obras que traducen las vivencias del espíritu; cada una de ellas registra una modalidad especifica que consiste en un diverso tipo de valores. Designaremos a la categoría correspondiente como concreción y su efecto en la obra cultural es la especificidad.

Por virtud de la concreción existen los diversos valores que pueden distinguirse con toda nitidez. Así tenemos a los valores lógicos, que expresan al pensamiento, junto a los valores éticos, que traducen a la voluntad, y los valores estéticos, que conciernen al sentimiento; la especificidad de los valores se origina en la facultad anímica donde se incuban. También se produce la especificidad del valor de acuerdo con las formas en que se realiza, y que en el caso de los valores lógicos corresponden a las ciencias y disciplinas del conocimiento; en los valores éticos a los sistemas morales y las formas de conducta; a las formas de representación y expresión artística, tratándose de los valores estéticos.

Además de estas especies, cuya objetividad es indudable, existen otras que se han aceptado con alguna reserva, como los valores religiosos, lingüísticos, pedagógicos, políticos, y otros más. No es éste el sitio para discutir cuáles sean las especies del valor, pero indicaremos que, mientras más se particularizan, la concreción axiológica es mayor, así como el número de ramas y subramas en los que se consuma la proyección axiológica. Por ello afirmamos, en términos generales, que los valores se realizan concretamente a través de varias especies, vale decir, que la concreción del valor se traduce en su especificidad.

La realización de los valores se efectúa en distinta magnitud, pues no todos los actos de la vida tienen el mismo valor. Esta diversidad axiológica se puede apreciar mediante la comparación de los valores, comprobando que se realizan en distinto grado. Designaremos a la categoría correspondiente como gradación.

El concepto de la gradación axiológica no denota la simple diferencia de nivel en la realización del valor, sino la dirección que representa su evolutividad. Si se ordenan sus diversos niveles de acuerdo a la evolución, se 
obtiene una sucesión de grados, determinada por el lugar que ocupan en dicha trayectoria. Ahora bien, cuando la gradación del valor es positiva, conduce al progreso, que es el incremento en la realización positiva del valor, mientras que en el caso contrario, la sucesión de grados mayores a menores produce un regreso, y la categoría es también inversa, o sea la degradación; por ello se dice que alguien se degrada cuando desciende en sus valores.

El concepto de la gradación axiológica puede ser cualitativo y cuantitativo, denotando en ambos casos un progreso en la realización del valor; en el primer caso se obtiene la depuración del valor, su limpieza de imperfecciones, para realizarlo en forma depurada, mientras que en el segundo queda el progreso a cargo de una insistente práctica.

Considerando que el valor es ante todo un producto del hombre, cae necesariamente bajo la limitación inherente de toda manifestación de lo humano. El valor se desenvuelve bajo ciertas circunstancias que son sus condiciones de validez, originando la circunscripción de los valores que designamos como relatividad.

La relatividad del valor principia con su definición puesto que en ella se circunscribe un modo de ser, según la especie axiológica de que se trate; esta condicionalidad es mínima y señala apenas el requisito necesario para especificar en qué consiste el valor. A partir de esta condicionalidad primaria, su realización en obras va señalando un incremento en la circunscripción, o lo que equivale, en su relatividad; la máxima relativización se produce en los actos concretos, que por su singularidad pueden considerarse irrepetibles.

De ahí establecemos la siguiente conclusión: la relatividad axiológica se inicia a partir de su definición primaria, señalando el tipo de valor que se trata; a partir de ella aumenta la condicionalidad, y por consiguiente, la relatividad, acercándose a su realización en actos concretos. La máxima relatividad del valor está en las acciones de la vida, que al mismo tiempo señalan el más circunscripto valor.

La relatividad axiológica señala las condiciones en las que vale y frente a las que ejerce su acción. Lo contrario de la relatividad sería la absolutez, o sea un valor incondicionado, perfecto y definitivo, que desde luego no produce el hombre. Al contrario, todo acto de valor está sujeto a condiciones que fijan su modo de valer, esto es, su relatividad.

La relatividad del valor hace que diversos elementos, no valiosos para cierto fin, se conviertan en un momento dado en los más valiosos, cuando se adaptan a las condiciones del acto; por ello la calificación del valor no se puede otorgar en forma absoluta, sino al contrario, está sujeta a las circunstancias concretas; todo vale en función de algo, ya sean condiciones fácticas o postulados remotos, y en cada caso se establece una forma de relativización.

Las categorías que hemos examinado hasta ahora corresponden a la esencia pura del valor; son condiciones para cumplir su validez intrínseca 
como expresión del espíritu. Sin embargo, los valores tienen otra virtud que consiste en aplicarse a la satisfacción de una necesidad; ésta puede ser del más diverso orden, desde las necesidades prácticas y materiales, hasta la más elevada y sublime necesidad espiritual, que también se presenta como un reclamo urgente en la vida. Esta categoría aplicativa es la que designamos como utilidad del valor.

Hemos dicho que las necesidades del hombre no son exclusivamente materiales, sino de todo orden, incluyendo principalmente las de tipo espiritual. Para comprender el significado de esta categoría hay que definir en términos generales lo que es una necesidad. Necesidad equivale a falta de un elemento necesario en la vida; este elemento puede ser material, y en tal caso la necesidad de comer o vestir, en cuyo caso los alimentos y la ropa representan un valor porque satisfacen dicha necesidad. El dinero tiene un valor económico más amplio puesto que sirve para adquirir los elementos que satisfacen todas las necesidades materiales; de ahi la gran importancia que se le concede.

Pero también hay necesidades de orden espiritual, como es la de adquirir cultura, de orientarse en la vida o comprender una situación determinada. En tales casos el valor que satisface esta necesidad podrá ser un libro, una conferencia, una cátedra o un diálogo y desempeñarán la función de valores espirituales, en la medida que satisfacen una necesidad del mismo orden. En cambio, para alguien que necesite hacer un viaje será de gran valor el vehículo que le permita realizarlo. $\mathrm{Y}$ así sucesivamente.

Uno de los problemas que presentan un perfil de mayor importancia en la valoración consiste en definir la prioridad que tienen ciertos valores frente a los demás. El examen del acto valorativo demuestra que no todos los valores poseen la misma significación, sino que unos la tienen en mayor grado que otros; esta prioridad axiológica motiva la categoría que designamos como jerarquia.

En todos los actos y situaciones hay una jerarquía; sin embargo, no es siempre la misma. Por el contrario, la jerarquía cambia de un sistema a otro, aun en los diversos actos de valoración, aunque correspondan a una misma persona y un mismo sistema. El motivo de esta variabilidad es que determinadas situaciones exigen la realización de cierto valor y sólo de él; si todos los actos de la vida presentaran las mismas necesidades no habría razón para esta mutable prioridad, que sería idéntica en todas las situaciones. En cambio, la variabilidad de circunstancias vitales origina el correspondiente cambio de valoración, que a su vez se traduce en la prioridad que adquieren los satisfactores de dicha necesidad. Así se establece una relación entre las circunstancias fácticas, las situaciones vitales, las necesidades contingentes y los valores de satisfacción.

Ahora bien, bajo determinadas circunstancias, cierta necesidad puede 
presentarse con el carácter de urgente, y el elemento que la satisface adquiere automáticamente un valor primordial, tiene jerarquía sobre los demás en virtud de la urgencia con que se presenta su necesidad. En otras condiciones la misma necesidad puede no ser urgente y el valor que la satisface, aun siendo el mismo, probablemente no posea ninguna jerarquía especial. Para un sediento en el desierto, su máxima necesidad es calmar la sed, y cuando ésta se agudiza al máximo se presentará con especial urgencia; un vaso de agua será entonces el máximo valor para ese individuo, que en condiciones normales no repararía en arrojarlo al suelo.

Concluyendo, la jerarquía de los valores consiste en la preferencia que admiten en virtud de la satisfacción que proporcionan de una necesidad primordial que se presenta con urgencia.

Hemos efectuado una breve exposición de las categorías axiológicas, entendiéndolas como conceptos que configuran la estructura de los valores. El empleo de dichas categorías permite manejar con fluidez los problemas del valor, pues al señalar determinada categoría se está indicando la propiedad general que actúa en ella, con todas las consecuencias que implica. Por ejemplo, al hablar de la síntesis axiológica se entenderá el proceso vinculatorio de lo real y lo ideal; al referirse a la idealidad del valor se trae a colación el mundo de las concepciones puras. La realidad denota el necesario contacto con la naturaleza, cuyos elementos sirven de albergue material a las ideas del espíritu. La polaridad nos revela esa inevitable contradicción que encierra la comunidad de lo bueno y lo malo. La unidad justifica el que a todos los valores se les llame así, a pesar de su innegable diferencia. La concreción contiene precisamente el factor diferencial que hace distintos a los valores y las obras que derivan de ellos. La gradación registra las variantes en calidad y cantidad, con la dirección positiva al progreso y la negativa al retroceso. La relatividad comprueba la circunscripción en que se encierra todo valor, ya sea como condicionalidad o como imperfección. La utilidad es el resultado pragmático que obtiene la satisfacción de las necesidades de la vida. Y la jerarquía sitúa la urgencia de dichas necesidades con una orden circunstancial de prioridad.

Todas las categorías se comportan de análoga manera, con una funcionalidad universal que es inherente e indispensable para la comprensión del valor. Refrendan el sentido clásico de las categorías como conceptos universales, que en este caso representan la universalidad de los valores. Su definitiva importancia consiste en que el sistema de las categorías axiológicas ostenta la máxima representación de la filosofía, del espíritu y de la existencia. Son el índice espectrográfico, la radiografía más fiel y elocuente de lo humano. 


\section{III}

El problema que se debate en toda la filosofía, relativamente a los conceptos de objetividad y subjetividad, no podía estar ausente de la cuestión axiológica, siendo ella tan delicadamente crucial que de su resolución depende la postura del filosofar. Los valores son la piedra de toque para la filosofía y determinan a todo el sistema puesto que tanto ella como la cultura en general, se fundan en el concepto de los valores. No extrañará que tan debatida cuestión obtenga un indefectible desenlace en la axiología, planteado en la siguiente forma: clos valores son entidades objetivas o son productos de la subjetividad?

De la respuesta que se otorgue dependerá la posición axiológica y la filosófica. Tiene ante sí la disyuntiva de objetividad y subjetividad; será objetivista en el primer caso, cuando sostenga que los valores son entidades con existencia y autonomía propia, en tanto que el segundo defenderá la posición inversa, afirmando que los valores son creados por el hombre y pierden sentido fuera de la subjetividad. Esta disyuntiva abarca a las posturas axiológicas, que pueden clasificarse en dos grandes géneros, objetivistas y subjetivistas, quedando pendiente cuál de ellas tiene la razón, si las dos son justificables o bien ninguna. Para contestar tan significativo problema se encaminan ahora nuestras reflexiones.

La actitud más espontánea frente a la cuestión de los valores consiste en definirlos como una libre elección del individuo, el cual sentirá afinidad por el valor elegido y los objetos que lo contengan; de ahí proviene la apetencia característica en toda suerte de valoración. La postura correspondiente, que defiende la prioridad del hombre, se formula diciendo que: el valor es la apetencia del sujeto; éste se vierte en los objetos que inciden en sus deseos, ya sea por afinidad intelectual, por inclinación emotiva o por urgente necesidad pragmática. Es natural que la doctrina subjetivista proclame la preeminencia del sujeto en el acto de la valoración, y, de acuerdo con su tesis general, puede adoptar la siguiente fórmula: el valor es un producto del sujeto; éste es el determinante del valor y posee definitiva prioridad sobre el objeto valorado.

Por su parte, la doctrina contraria, o sea el objetivismo, defiende a los objetos sosteniendo que a ellos corresponde la prioridad, puesto que para efectuar la valoración necesita haber un objeto que la inspire; en otras palabras, el valor radica en los objetos y el individuo se limitará simplemente a constatarlo, a reproducirlo mediante la acción consumatoria que sucede al acto valorativo. La doctrina objetivista es en todo contraria a la subjetivista; por ello, a la anterior afirmación del sujeto corresponde ahora la del objeto, con la misma preeminencia que se atribuye al ser humano en el subjetivismo. Lo principal para el objetivismo es el objeto que contiene 
el valor, quedando éste como una propiedad implícita de aquél. El sujeto no hará sino reconocerla y dejarse llevar por lo que encuentre en ella.

El subjetivismo axiológico se apoya fundamentalmente en el hecho innegable de que los valores son fruto de una elección humana, que depende a su vez del carácter y las circunstancias que rodean al individuo. Esta directa intervención no puede soslayarse ni sustituirse por ningún otro elemento, pues la valoración es siempre un acto que efectúa el hombre, deriva de su naturaleza y depende de ella para su ejercicio.

En efecto, ¿qué sentido podría tener un valor fuera de lo humano? Imaginemos por un momento que la Tierra estuviera despoblada de hombres; los objetos no tendrían el valor que actualmente representan por la sencilla razón de que no habría quien los pudiera estimar. Tal vez pretenda alguien sostener que el desarrollo de la vida vegetal y animal podría encerrar una especie de valor, pero esta hipótesis se aleja por completo de la problemática en la cual se asientan los valores, que son definidos precisamente como valores del hombre, realizados para su beneficio y usufructo.

Hablando en rigor, el planteamiento axiológico no puede efectuarse a espaldas de lo humano, puesto que desde un principio se define a los valores como entidades valiosas para el hombre, y por consiguiente, pierden su auténtico sentido cuando se les ubica fuera de él. Tal vez parecería un círculo vicioso postular al valor en los términos de su relación humana y posteriormente definirlo en virtud de la propia relación; sin embargo, esta dualidad no hace más que refrendar la consideración humana del valor. ¿A qué se debe, entonces, el énfasis del subjetivismo sobre la necesidad de acudir constantemente al hombre? El motivo es que, a pesar de la original y permanente afirmación de lo humano, hay siempre un correlato objetivo en el cual se deposita el valor, de suerte que aun afirmando su ineludible humanitariedad, subsiste el requerimiento del objeto que, puesto frente al sujeto, refrenda la cuestión: ¿es el valor exclusivamente un producto del hombre o una propiedad de los objetos?

Sabemos que el subjetivismo decide lo primero, o sea que el valor radica en la elección y la preferencia del sujeto, como una facultad suya que por ningún motivo se le puede separar. No obstante la acción significativa que ejerce el carácter en la valoración, ésta no se limita simplemente a la afinidad con el valor, sino también implica su reconocimiento objetivo, admitiendo que el objeto de la valoración posee una cualidad en cuya virtud el valor mismo le es conferido. Este objeto forma el correlato material y por él adquiere la axiología un criterio normativo, superior a la preferencia incidental que fluctuaría con la constante oscilación del carácter. En el subjetivismo extremo, los valores dependen del estado de ánimo, de las circunstancias en las que se deambula continuamente el individuo, y la consecuencia de semejante mutabilidad, en caso que fuera absoluta, tendría incalculable 
repercusión; la unidad de la vida se perdería definitivamente en un continuo vaivén, en el desconcertante peregrinaje de una situación a otra, y en vez de valores habría exclusivamente individuos sujetos a la transitoriedad del carácter, a la circunstancialidad del momento.

La propiedad objetiva del valor destaca al observar que la elección se dirige a un objeto, y que si bien el individuo es determinante en su origen, no podría efectuar la acción valorativa si no fuera porque en el objeto hay una virtud que le incita a la valoración. Esta virtud es la objetividad, y puede expresarse como la propiedad que tiene el objeto de atraer la preferencia del sujeto. Se ha discutido mucho hasta qué punto subsiste la objetividad, pero priva un acuerdo de principio sobre la existencia del valor, esto es, sobre la realidad que se presenta al sujeto e inspira su apetencia, con la correspondiente elegibilidad que es su base fundamental.

El planteamiento objetivista y subjetivista, que se ha manifestado alternativamente en la axiología, proviene del enfoque similar efectuado en la problemática filosófica, que ha sido vista a través de dos cristales que se dirigen al mundo externo y al mundo interno, respectivamente. Cada caso ha producido una tendencia a extremar su punto de vista mediante el aislamiento del contrario, degenerando en la unilateralidad y el antagonismo que tantas veces se ha comprobado.

En el caso del valor, esta unilateralidad se refrenda en las posturas respectivas, y su consecuencia directa se manifiesta, en el objetivismo, como afirmación terminante del objeto valorado, con el consiguiente rechazo de la intervención subjetiva. Por su parte, el subjetivismo se decide por la afirmación del sujeto valorante y pretende incluir en él a todos los elementos de la valoración, quedando el objeto en calidad de reflejo accesorio de la subjetividad.

Las dos tendencias acusan una posición extrema, que consiste, en el primer caso, en un dogmatismo que materializa al valor y lo estatifica mediante una hipóstasis ontológica, según la cual el valor está dado en el objeto y permanece inmutable, con independencia de la valoración subjetiva. Por el otro lado, la defensa del sujeto desemboca en un escepticismo, y reduce el marco de la valoración a las circunstancias psicológicas en que se efectúa, imposibilitando fijar un punto de vista suficientemente definido para rescatarlo de las oscilaciones temperamentales del carácter.

Para no caer en un amorfo eclecticismo en torno a este problema, conviene subrayar que se trata de dos asuntos diferentes; el objetivo concierne a la realidad del valor, mientras el subjetivo se refiere a la forma de ser captado. Diríase que al hablar de la realidad del valor estamos prejuzgando sobre lo que se trata de resolver, puesto que precisamente se quiere saber si el valor es algo real; empero, la cuestión no admite dudas, pues la realidad del valor corresponde a la realidad del objeto y si la existencia de este últi- 
mo es comprobada, se admitirá un tipo de valor objetivo, cuya percepción podrá cambiar de acuerdo con las circunstancias y la sensibilidad de quien lo perciba.

El problema se define separando las funciones de objetividad y subjetividad como dos facetas distintas, quedando la primera como entificación del objeto que contiene al valor, en tanto que la segunda se refiere a la disposición que priva para captar dicho valor. Es importante señalar ese distingo, pues sólo a partir de él se apuntará a una posible solución; hay que tener presente que la funcionalidad del valor le circunscribe a ciertas condiciones de realización y esta condicionalidad le sustrae definitivamente cualquier carácter absolutista, aunque por ello no quedará sujeto a las circunstancias oscilantes de cada individuo.

La posibilidad interpretativa es de primordial importancia cuando se quiere establecer la objetividad del valor; si la obra es dada como creación de un sujeto y la contemplamos en el seno de una vivencia subjetiva, es necesario un doble recurso para rescatar al contenido axiológico de este marco subjetivista y develar la expresión que su autor depositó en ella. El motivo más poderoso para insistir en este requisito es que toda obra ha sido creada para realizar un valor objetivo, incluyendo los casos en que la obra se presenta como una confesión personal o expresión de un evanescente estado de ánimo.

Pero aun en estos casos, la obra queda sujeta a la virtud del contemplador, como algo dado y producido en el mundo, como una realidad que es posible tener abiertamente a disposición; aun cuando la vivencia creadora haya desaparecido, la obra queda en pie y es captada en función de su valor, de análoga manera a como podrían hacerlo sus contemporáneos. Esto es lo que sucede, por ejemplo, con los grandes testimonios de la historia, cuya interpretación se funda en la hermenéutica del valor, en una reconstrucción que en última instancia tiende a reproducir la unidad cultural que se conoce como espiritu histórico.

El problema de la objetividad y subjetividad de los valores se relaciona estrechamente con la estimación de la existencia, en cuanto realidad que se dirige a determinadas perspectivas que actúan con una función direccional, con objeto de superar el estado que manifiesta la realidad del ser humano. Se trata del dualismo reconocido clásicamente como oposición del ser y el deber ser, lo que es en realidad y lo que debe ser de acuerdo a los principios normativos. Esta oposición es la base dinámica de la evolución, pues sin el planteamiento de una exigencia en calidad de deber ser, no había ninguna iniciativa para superar un estado de cosas y orientarlo al nivel superior. Por ello, la normatividad del deber ser es la base de la superación humana.

Ahora bien, este dualismo se refleja en la subjetividad de los valores, en el ser y la existencia del hombre, o sea el momento vital que envuelve de 
facto al individuo y lo manifiesta de acuerdo con sus propias circunstancias, que son predominantemente subjetivas y obedecen a hechos concretos de naturaleza individual. Por el contrario, la objetividad se manifiesta como deber ser, porque encuentra una justificación racional de su valor, con independencia de la realización que haya adquirido en la existencia. El deber ser es la norma, la justificación objetiva y universal, la perspectiva abierta y libérrima que se postula como dirección de la vida.

En tal sentido, el hombre se sitúa ante la disyuntiva de quedar enclavado en el ser, o por el contrario, orientarse al deber ser; la primera actitud representa la posición estática en la vida de quien es como es, y quiere seguir siéndolo, sin mayor inquietud por enjuiciar su propia realidad. Por el contrario, la segunda de las posiciones reconoce al deber ser como un plano más elevado por cuya conciencia de valor se dirige a su conquista. Por ello, la base para progresar radica en el valor y fuera de él pierde impulso la existencia, hasta convertirse en un renunciamiento al deber ser, lo cual equivale a la permanencia estática y definitiva en el ser.

La orientación debe ser objetiva y dirigirse al mundo de los valores a través de una comprensión racional y no de un simple abandono a la facticidad. Hay siempre una diferencia entre el ser y el deber ser, que en este caso equivalen al estatismo y al progreso; el primero acusa una marcada predilección para acoger los valores subjetivos, o sean las inclinaciones personales que se elevan al rango de valor por una convicción particular que recae casi siempre en el terreno del individualismo. Por el contrario, la postura objetiva está continuamente en guardia frente a dichas inclinaciones y llega a considerarlas como amenaza para la seguridad vital.

La actitud filosófica coincide con la objetividad, pues admite como base a la razón; el motivo de orientarla conforme al criterio racional consiste en la firmeza que proporcionan los valores objetivos, en vista de su justificación universal y necesaria; en cambio, las inclinaciones subjetivas quedan en estrecha dependencia con respecto a la mutabilidad e incertidumbre del carácter.

De acuerdo con lo que hemos dicho, el acto de la valoración está ubicado en un marco preciso y circunscrito a las condiciones que lo rodean. Tanto el valor establecido como el acto mismo de la valoración adquieren sentido en virtud de un sistema que le da proyección vital e inmanente a la existencia; fuera de él pierde su auténtico valor y se convierte en una abstracción inoperante, como sucede cada vez que se han querido introducir arbitrariamente los conceptos axiológicos en un lugar que no les corresponde. Cualquier elemento, ya sea objeto de la naturaleza, obra del hombre o concepción del intelecto, puede figurar en calidad de valor, siempre y cuando esté situado en el punto que le corresponde dentro de un sistema de valoración. 
Así, pues, la virtud del valor se determina en el seno de un sistema valorativo donde participan diversos factores; no es una propiedad abstracta ni absoluta, que pudiera subsistir incondicionalmente, sino al contrario, se trata de una función, o lo que equivale, de una propiedad relacionante. Todo valor lo es en función de ciertas condiciones y fuera de ellas desmerece y puede inclusive convertirse en un contravalor, o sea un valor negativo, que contradice la función adquirida en su propio marco de valoración.

La funcionalidad del valor no es más que un caso particular de la funcionalidad más amplia, que se manifiesta en toda clase da actos y propósitos de la existencia; esta funcionalidad consiste en la serie de condiciones que dan sentido a los actos y motivos que se persiguen y fuera de ella quedaría como una entidad amorfa e indiferenciada. Los requisitos y condiciones fijan el sentido del valor, por cuya virtud limitativa se circunscribe al campo en el cual tiene validez.

Este campo de requisitos y limitaciones, pero al mismo tiempo de posibilidades y fundamentos, es el que designamos como sistema de valoración y, de acuerdo con lo dicho, se definirá como el conjunto de circunstancias que concurren para que un elemento determinado obtenga la categoría de valor. Por otra parte, sabemos que un valor es un elemento que concierne al hombre, ya sea directa o indirectamente, en grado superior o en forma rudimentaria. El carácter axiológico está determinado por su incidencia en los intereses del hombre, dentro del cuadro condicionante que designamos como sistema valorativo; éste es el que define la peculiaridad con que dicho elemento participa en la esfera de los intereses humanos. El sistema valorativo se establece al definir los elementos que lo constituyen y que son al mismo tiempo las circunstancias de la valoración.

$\mathrm{La}$ exposición del sistema valorativo tiene dos aspectos; el primero es el aspecto general y radica en las condiciones que determinan todo acto de valor; el segundo es el aspecto particular y estriba en el análisis de los actos concretos, definiendo a qué se debe la realización y aceptación del valor. La problemática se escinde en esos dos grandes apartados, el general y el particular, que en sus extremos admiten una consideración específica; el de la primera consiste en la apreciación universal de los valores, en tanto que el de la segunda radica en la casuística, o sea la comprensión de cada acto singular.

Miguel Bueno 